\title{
Developing mindfulness in children through participation in music activities
}

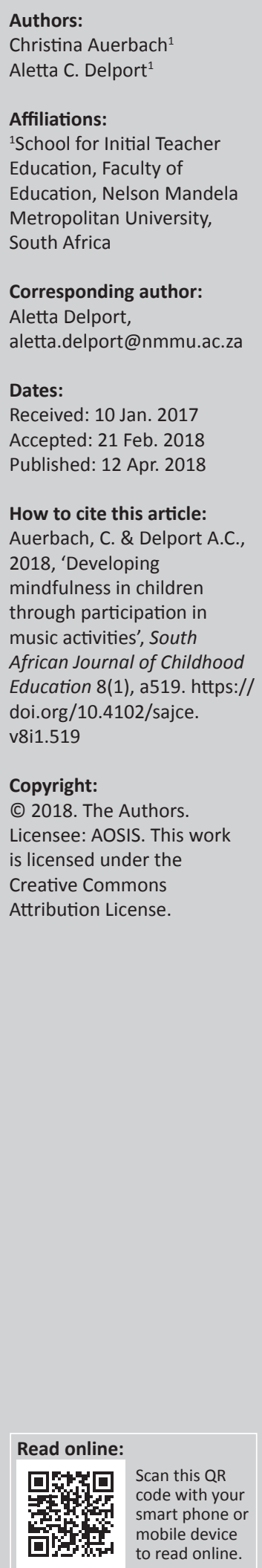

The vast majority of young South African children grow up in socially- and economicallychallenging settings. These impeding conditions hamper their intellectual growth and affect their physical, mental, emotional and spiritual well-being. Increasingly, mindfulness is being recognised as a means to enhance holistic well-being of children. Likewise, music is widely acknowledged for its potential contribution to the holistic development of children. In this article, we reflect on a non-formal music programme, implemented on a weekly basis over a period of 10 months, at an aftercare facility in an impoverished township area in South Africa. Our aim was to develop, through the children's active participation in music activities, some aspects of mindfulness. Data were generated through personal observations, field notes and semi-structured interviews. Two salient themes emerged, namely, enhanced awareness of self and others, and improved listening and attention skills. These are key aspects of mindfulness. We subsequently argue that aspects of mindfulness in young children can be developed through focused activities centred on music and sound.

\section{Introduction}

The vast majority of young South African children grow up in socially- and economicallychallenging settings. These impeding conditions hamper their intellectual growth and affect their physical, mental, emotional and spiritual well-being. Increasingly, mindfulness is being recognised as a means to enhance holistic well-being for children. Likewise, music is widely acknowledged for its potential contribution to the holistic development of children (Kokotsaki \& Hallam 2011), offering them 'life, hope, the prospects of discovery, light, and ultimately, healing' (Greene 1995:133). Focused involvement with music develops listening skills. Engagement with musical sound can thus facilitate mindfulness, as it enables 'attentive awareness, yet generous and indulgent engagement with the present moment' (Feldman et al. 2007:177).

Unfortunately, children today grow up in a society of fast increasing and changing electronic technology, polluted with noise. As such, they have learnt to curb the impact on their auditory senses, 'excluding sounds from awareness' (Deason-Barrow 2013:3). Although they may 'hear', they do not necessarily 'listen' attentively, thus foregoing the multiple benefits engagement with music can offer. Several research studies furthermore indicate that, in the majority of South African schools, music education is not properly implemented, further depriving young South African children of music's potential contribution to their holistic development and wellbeing (Cloete \& Delport 2015; Delport \& Browne 2015; Vermeulen 2009).

In this article, we reflect on a non-formal music programme implemented on a weekly basis over a period of 10 months at a voluntary aftercare facility in an impoverished township area in the Southern Cape, South Africa. Our aim was to, through their active participation in musical activities, develop some aspects of mindfulness in these young children, aged 11-14 years. The findings of our study enable us to argue that through active involvement in music activities, mindfulness in young children can potentially be developed. Before we continue to report on the study, it is now important to clarify the concept of 'mindfulness'.

\section{Mindfulness}

Mindfulness is generally regarded as the intentional cultivation of focused moment-by-moment, non-judgemental attention and awareness (Baer, Walsh \& Lykins 2009; Brown, Ryan \& Creswell 2007; Grossman et al. 2004; Kabat-Zinn 2003; Malinowski 2013). It implies: 


\begin{abstract}
... a process of regulating attention in order to bring a quality of non-elaborative awareness to current experience and a quality of relating to one's experience within an orientation of curiosity, experiential openness, and acceptance. (Bishop et al. 2004:234)
\end{abstract}

Mindfulness thus serves as a receptive vehicle. It is about being fully engaged in the present moment, rather than being in a distracted mode, daydreaming about the past or future, or caught up in reactivity. When in a state of mindfulness, the mind is open, enquiring and curious. It is free of judgement and reactivity. Mindfulness thus primarily implies the ability to 'step back', detaching oneself from transient thoughts, opinions and emotions. Enhanced insight into habitual responses and belief systems enables release and nonattachment to these belief systems, subsequently improving satisfaction with life, well-being and interpersonal functioning (Beach et al. 2013; Fresco et al. 2007a, 2007b; Huston 2011; Sahdra, Shaver \& Brown 2010; Vago \& Silbersweig 2012).

Research indicates that a person who regularly practises mindfulness-based meditation forms connections in the brain which enhance communication between different parts of the brain. Increased grey matter density develops around the hippocampus (associated with learning and memory), as well as around structures associated with self-awareness, compassion and introspection (Burke \& Hawkins 2012). Mindfulness practice also boosts the immune system, brain and nervous system, and aids in relieving eating and sleeping disorders (Greeson 2009). Mindfulness enhances one's perception capacity and ability to discern what is real and imaginary. It contributes to: well-being; reducing stress; improving communication, creativity and cognitive flexibility; and nurturing compassion and altruism. It helps us to recognise that we are accountable for our own life experience, giving us the tools to shift into a new way of being, behaving and seeing the world. In doing so, anxiety levels are reduced. Several researchers (Baer et al. 2009; Brown et al. 2007; Bunting 2015; Grossman et al. 2004; Hassed \& Chambers 2015; Malinowski 2013) thus concur that mindfulness improves overall wellbeing, equanimity and regulation of emotions. Ultimately, it helps us to become fully aware of the present moment.

From the above, it is evident that mindfulness holds several advantages for those who practise it. It is clearly also beneficial for children, especially for those who grow up in stressful conditions, as it allows them to relate to their internal and external experiences in ways that are present-centred, objective and responsive, rather than past/future-focused, subjective or reactive (Evans \& Schamberg 2009; Hedges \& Woon 2010). Mindfulness training enables children to explore and experience themselves 'from the inside'. It helps them to tap into other intelligences (Gardner 2011), embracing the knowledge that the capacity for social and emotional learning resides not only in their heads but also in their hearts (Burke \& Hawkins 2012). In this regard, Napoli, Krech and Holley (2005) report that teachers who had implemented mindfulness practices in their classrooms noted learners' improved attentiveness, creativity and serenity. Their learners experienced less anxiety before taking tests, made better decisions when in conflict and could re-direct their attention when off-task. The learners further exhibited cognitive flexibility and were able to use information more efficiently to enhance memory for instructional retention. Similarly, Meiklejohn et al. (2012) argue that mindfulness practices in schools foster pro-social behaviour, as they strengthen selfregulation and impulse control. They alleviate the effects of stress that obstruct learning and provide a skill set that promotes intellectual, physical and emotional well-being throughout life. Essentially, mindfulness thus espouses:

... the highest function of education: to bring about an integrated individual who is capable of dealing with life as a whole. (Burke \& Hawkins 2012:39)

Many South African children today grow up in stressful social conditions. Excessive stress, however, damages the structure of the developing brain, rendering these children vulnerable to lifelong problems in learning, behaviour and overall health (Evans \& Schamberg 2009; Hedges \& Woon 2010). The need for stress release and calmness of mind is real and significant. In this regard, mindfulness offers assistance, owing to its core focus on development of the child's ability to fall still and be present in the current moment (Baer et al. 2009; Bishop et al. 2004; Brown et al. 2007; Feldman et al. 2007; Hassed \& Chambers 2015; Kabat-Zinn 2003, 2005; Malinowski 2013). The benefits of mindfulness training in the classroom are therefore numerous. Apart from alleviating environmental stressors which can include, for example, family system disturbances, peer interaction conflicts and socio-cultural components, mindfulness can also improve children's presence of mind, clarity of thought, creativity and cognitive flexibility. Hence, it is our contention that mindfulness can and should constitute the basis of a more conscious education where the needs of the whole human being are integrated into the curriculum.

Mindfulness, however, develops over time and requires regular exercise. Training programmes normally aim to increase focused attention, social competencies and emotional self-regulation. These exercises typically direct attention to the breath, as rhythmic breathing regulates the autonomic nervous system, focuses the mind and increases self-awareness, contributing to emotional well-being (Napoli et al. 2005). Meiklejohn et al. (2012), as well as Napoli et al. (2005), believe that mindfulness training can easily be implemented in the classroom. This can happen in the form of daily breathing, body awareness, as well as stillness and focused listening exercises. In our research study, mindfulness training primarily involved focused attention on music and sound, as we contend that music is unique in its inherent power to affect human thoughts and actions, as further explored in the paragraphs below.

\section{Music and sound}

Music, according to Menuhin and Davis (1979:43), cultivates 'greater maturity, awareness and equilibrium in our civilization'. This knowledge was recognised and practised centuries ago by ancient sages and civilisations across the world, using music and sound for healing, moral 
and spiritual purposes (Bicknell 2009; Goldman 2002; Newham 1999; Thram 2013). Later, during the European Renaissance period, Marsilio Ficino (1433-1499), head of the Platonic Academy of Florence, revived aspects of these ancient practices, including the early art of improvised invocation used to harmonise the human soul with the cosmos, reminding the soul of its true origins in God (Voss 2001). Ficino also maintained that if two notes are perceived as two, then hearing is offended. He described a perfect harmony as one in which several notes are brought perfectly into one note. This occurs when one of the notes in some way absorbs the other into itself or joins it to itself. This can only be achieved by virtue of certain ratios of frequency that therefore produce sound that is unifying.

Since ancient times and across all cultures, music was clearly held sacred, providing man with a sense of beauty and perfection that could be aspired to.

During the late 18th and early 19th centuries, German physicist, Ernst Chladni (1756-1827), who was also a musician, explored the effect of musical sound vibration on matter. He demonstrated that when a violin bow was drawn over the edge of a metal plate and a pure sound created, sand grains or poppy seeds loosely spread over the flat plate took on symmetrical forms (Campbell 1997). Berendt (1983:91) describes this phenomenon as sound calling the particles to order, explaining that 'vibration calls matter to order. Like a potter shaping clay at the wheel, sound shapes us and sculpts us both inside and out'.

During the 1960s, the study of the effect of vibration on matter was taken further by Jenny (2001) and referred to as 'cymatics'. Jenny captured photographically extraordinary images that mirrored biological forms created through sound vibration in liquid glycerine.

Today, several researchers (Goldman 2002; Khan 1996; Le Mee 1994) regard the human body as a living entity of vibrations. The subtle vibrations of certain musical sounds produced by the human voice serve as a delicate, internal 'massage' of all the body's cells. Prolonged vowel sounds resonate in particular parts of the body, which can be felt clearly when there is listening with awareness. Biological rhythms such as breathing and heartbeat synchronise with each other, reducing a person's energy consumption. Moreover, just as human beings entrain to surrounding natural rhythms, such as the sounds of the ocean (Ramirez et al. 2016), the natural process of entrainment takes place in communal singing and sounding which helps to explain the unifying and calming effects of prolonged vowel sounds and pure harmonies (Leeds 2010).

In recent years, general interest in the power of musical sound re-emerged. In 1997, Don Campbell proposed the so-called 'Mozart Effect', suggesting that when one listens to the music of Wolfgang Amadeus Mozart (1756-1791), brainwaves are slowed down and equalised, generating a heightened state of calm and awareness. Memory and learning abilities improve. Subsequently, the immediate environment is experienced as more spacious, lighter, elegant, resourceful and ordered. A person's breathing slows down, the immune system is strengthened and digestion stimulated. Ultimately, stress is reduced and productivity increases (Campbell 1997). Although initially met with scepticism, Campbell's postulations (1997) have since been supported and expanded by numerous recent interdisciplinary research studies, confirming the beneficial impacts of musical encounters on human beings (Leeds 2010). Active participation in music activities generates greater self-reliance and more positive attitudes, especially of low ability, disaffected children (Kokotsaki \& Hallam 2011). Regular involvement in group music activities furthermore improves social adjustment and cohesion amongst children participating in these activities (Ings, Jones \& Randell 2000; Kokotsaki \& Hallam 2011).

It is our contention that each human being has been bestowed with musical intelligence and potential (Gardner 2011), to be accessed and applied toward improving his or her quality of life, as well as that of others (MacLaren 2013). Opportunities thus need to be available for human beings, especially young children, to retrieve, develop and benefit from this inherent, natural 'gift'.

\section{Research aim}

In light of the above, further investigation into the curative, transformative impact of regular musical sound experiences on South African children, especially those living in stressful contexts, felt appropriate. More specifically, we wanted to ascertain how regular involvement in music activities can cultivate mindfulness, integrating 'body, mind and spirit', subsequently facilitating holistic development that will enable children to overcome their challenging social circumstances.

\section{Research methodology}

This research study was qualitative and interpretive in nature (Creswell 2013; Maxwell 2012). The research took place at a voluntary aftercare facility in an impoverished township area in the Southern Cape, where alcoholism, teenage pregnancy, drug abuse and unstable family situations were prevailing challenges, affecting the development and well-being of young children, including those who attended the aftercare centre. The participants were thus conveniently selected, as they 'happened to be available and accessible at the time' (Cohen, Manion \& Morrison 2007:114). Over a period of 10 months, Christina, as volunteer, worked with a group of 12 children which included both male and female learners between the ages of 11 and 14 years. Participation in the study was entirely voluntary, as was attendance at the aftercare centre itself. Before the study commenced, a meeting was held with the parents/guardians and children, explaining the nature and intention of the programme, obtaining consent from the participants and their parents/guardians.

\section{The music programme}

The 10-month weekly programme was divided into different afternoon activities, all with the underlying intention to bring 
the mind to rest in a state of focused attention, practising mindfulness. The first two sessions introduced the main aspects of the intervention programme, namely, sounding, learning an instrument and the language of music. After the first few weeks, we settled into a routine where a typical lesson would begin with a sense-connecting exercise and a 'talking stick' to encourage communication and listening. We then sounded and practised harmonies, whereafter we exercised the fingers with rhythm and rhyme, followed by recorder playing. The session finished with a story and discussion.

In essence, all the activities were aimed at developing listening skills in order to enhance the children's ability to be fully aware and present. Through the sustained practice of repeating the same exercises every week for a period of 10 months, it was hoped that their ability to develop mindfulness would gradually improve.

\section{Generation of the data}

Data were generated on an ongoing basis through personal observations and field notes. Towards the end of the programme, semi-structured interviews with the children, as well as Jayden, the aftercare teacher, and Lilanie, the aftercare supervisor, were also conducted. The data were then analysed and salient themes identified, applying the thematic analysis method as proposed by Braun and Clarke (2006).

In essence, the data indicate that over the 10-month period during which the children participated in the programme, they developed aspects of mindfulness. These included focused attention and active listening, unity of experience and inner discipline. In the subsequent paragraphs, the data will first be presented and discussed according to the specific strategies employed. Thereafter, two salient themes that emerged during the data analysis will be discussed.

\section{'Vowel sounding'}

The 'vowel sounding' exercises included attentive listening to music sounds, the singing of basic harmonies of doh, upper doh, as well as the singing of intervals of the fifth and third in various combinations. The children were required to listen attentively to the sounds, the silences between the sounds, as well as different sounds vibrating in different parts of their bodies (Glennie 2003).

It became apparent that the 'vowel sounding' exercises facilitated mindfulness owing to their strong emphasis on focused listening and the nature of the vowel sounds themselves. During his interview, Bezile ${ }^{1}$ noted that these exercises helped him to get his 'ears tuned up'. He then described a particular moment when all the children, after managing to sound together in harmony spontaneously applauded: 'we liked it ... a strong feeling. We were there, and we sung together and it was good'. Mahlumbandile, in his interview, also mentioned the particular event. For him, 'it was beautiful'. Lulama also referred to the particular

1.Pseudonyms will be used throughout. incident, describing it as 'joyful' and an activity that they 'all liked'. In her response, Khutala mentioned that she experienced 'happiness' when they all sounded vowels as a group. The children's responses thus confirm Maclaren's (2013) postulation that when sounding and listening to pure sounds with the precision of attention, joy naturally arises.

\section{'Connecting with the senses'}

The 'connecting with the senses' exercise was essentially designed and implemented to bring the children to stillness and into the present moment. This activity did not involve music per se. The children were encouraged to focus on their breathing and other sensory experiences. They were asked to sit upright, close their eyes and focus on the different senses one by one. Instructions included, for example:

Sitting balanced and upright, become aware of the connection between your feet and the floor...

[Pause].

Feel the weight of the body on the chair...

[Pause].

Be aware of the touch of clothes on the skin and the movement of air on the face and hands...

[Pause]

Experience the sense of taste in the mouth...

[Pause]

Be aware of smell...

[Pause]

... and the movement of breath in and out of the body...

[Pause]

Listen to all the sounds in the room, extend that listening to sounds outside of the room and outside of the building...

This was then followed by a few moments of just sitting still. The children were also encouraged to practise this exercise at other times and observe the effect it had on their being.

Similarly, our data reveal that the 'connecting with the senses' exercise brought the children's minds to rest and helped them to focus on the present moment. Bezile, in his interview, said that the exercise 'made me feel calmer ... it is like keeping yourself clean'. Diallo noted that the exercise soothed him and then mentioned that he often practised it during times when he did not have anything else to do. Lilanie, the aftercare supervisor, during her interview described an incident where she did the exercise with all the children at the aftercare centre. She observed that it comforted them considerably. The activity served as a form of therapy, offering the children calmness of mind. The responses thus confirm this activity's curative potential, as it afforded the children the opportunity to fall still and be fully aware in the present moment, a core aspect of mindfulness (Baer et al. 2009; Bishop et al. 2004; Brown et al. 2007; Feldman et al. 2007; Hassed \& Chambers 2015; KabatZinn 2003, 2005; Malinowski 2013).

\section{Recorder play}

The recorder was also introduced and the children also participated in finger exercises. During these activities, they were also introduced to basic music literacy. Playing 
the recorder requires inner discipline in terms of posture, obedience to what is taught and a willingness to practise and to maintain fine listening and attention. It also demands group consciousness, as individuals have to learn to play together. In addition, it requires patience when others in the group are receiving attention or struggling.

Our data reveal that most children enjoyed the recorder playing activities most. Bezile, during his interview, described the recorder sound as 'joyful'. Nofoto felt 'great' when playing the recorder, while Diallo said 'it is "kind" (sic) to learn the recorder'. Of particular interest in this regard was the observation of the supervisor, Lilanie, who noted the children's increased commitment to school homework, which she ascribed to improved focused attention and listening skills developed during the recorder lessons. The children exhibited a sense of achievement, and when asked if they would like to continue with recorder lessons in future, all hands went up without hesitation. The data thus indicate that the recorder playing activities developed aspects of mindfulness such as inner discipline, attentive listening and focussed attention as well as enthusiasm and natural joy (Baer et al. 2009; Brown et al. 2007; Hassed \& Chambers 2015; Malinowski 2013; Tunstall 2012).

\section{Data analysis and discussion}

It is our premise that the programme has shown that sounding exercises and musical practices, coupled with the promotion of active listening, helped to develop certain qualities of mindfulness such as improved listening skills, social skills, focused attention, increased inner discipline, teamwork, sense of unity and inner growth in terms of confidence, creativity and communication skills. Enthusiasm and learning from others was also observed. In this regard, two prominent themes associated with mindfulness emerged, namely, the participants' increased awareness of self and others, as well as the core role of listening in children's mindfulness practice.

\section{Theme 1: Increased awareness of self and others}

Firstly, the children's active engagement with music and sound clearly enhanced self-awareness. In this regard, the 'connecting with the senses' exercise helped to focus attention, which led to a state of calmness and presence of mind. Similarly, the vowel sounding practice combined with fine attention and listening had a healing effect on a subtle level. Ultimately, mindfulness allows access to clarity and reason. It improves well-being, creating a state of level-headedness and reducing reactivity and attachment to conditioned patterns of thinking. It relieves stress and increases selfawareness, insight and compassion (Hassed \& Chambers 2015). Vago and Silbersweig (2012) subsequently assert that mindfulness training decreases chances of psycho-pathological outcomes by reducing stress. An overactive or inefficiently managed stress response can lead to many long-term adverse effects such as immunosuppression, cardiovascular dysfunction and disease, accumulation of abdominal fat, loss of bone minerals, reproductive impairments and disorders of the nervous system (Vago \& Silbersweig 2012). Mindfulness practice can provide automatic forms of regulation or balance when a person is confronted with emotional or physical stress (Nugent et al. 2011).

Secondly, it became evident that the music programme enhanced the children's awareness of others, confirming the postulations of Kokotsaki and Hallam (2011) as well as Ings et al. (2000) that group music activities enhance social inclusion and cohesion. During the group recorder sessions, the children clearly experienced a sense of mutual connection when making music together. The example of all the children clapping spontaneously after sounding a pure harmony is a case in point. Harmony arises when the proportions of something perceptible through its qualities and degrees match up and harmonise at every point with the proportions that constitute the combination of the particular sense with spirit (Fellowship of the School of Economic Science 2003). This state was recognised by the children in a particular moment of perfect harmony powerful enough to be recalled later during individual interviews. A sense of unity, achieved through listening to and sounding these ratios with presence of mind, exemplifies a state of heightened mindfulness. In a similar vein, the principle of sympathetic resonance (Beaulieu 1987) was at play during these moments of unity, as was the process of entrainment described by Goldman (2002). The data thus confirm the postulation of Vago and Silbersweig (2012) that mindfulness practice extends awareness beyond oneself to also encompass the physical and emotional state of another.

\section{Theme 2: The core role of listening}

Active and attentive listening is inherent to the development of both music and mindfulness practices. It refines the degree to which a person can become fully aware of and present in the moment with focused attention on what is being heard, rather than on commentary in the mind or being distracted by noisy surroundings. It enables access to reason in a state of chaos, providing new tools to improve focus in noisy and scattered, or distracting environments.

Active and attentive listening is also core to the process of education. Focused listening capabilities enhance learning. In reality, formal education in South Africa at present is predominantly delivered orally and as such, learning in the classroom depends on good listening skills (Hornickel et al. 2012; Tallal 2012). When auditory processing is hampered, learning is affected. In this regard, a growing body of evidence links children's reading failure to auditory processing disorders. Subsequently, research has indicated clear benefits of including auditory intervention for struggling readers. The more proficient children become in learning to listen, the more capacity they have for listening to learn (Tallal 2012).

It is often incorrectly presumed that we listen solely through our ears. Vibration can also be felt. In reality, information from distortion in airwaves is transformed into electrochemical potential, travelling down the neurons towards the central nervous system where it is interpreted. Hence, we do 
not experience reality directly through the senses but through the brain's interpretation of the signals from the senses. It depends, however, on which area of the brain receives the message as to whether something is seen, heard, felt, tasted or smelt. The information the brain receives is distorted by the filters over each sense in terms of sets of experiences, thoughts and memories that are still charged, creating emotional reaction, prejudices, belief systems and attitudes. In essence, we experience what we believe (Lipton 2005). In this regard, Glennie (2003) and Goldman (2002) assert that human beings need to learn how to use their bodies as resonating chambers, listening to themselves, other people and life around them without judgement or criticism.

Another prominent theme that emerged was the importance of listening activities in mindfulness programmes for children. The data clearly indicate that the activities included in the study assisted the children acquiring these skills to varying degrees. The listening activities clearly enhanced their personal discipline and sense of accomplishment. When their listening was focused, their sense of well-being improved. They felt 'good', 'joyful' and 'happy'. Learning to listen and focus appears to have provided new resources for them to draw on.

\section{Conclusions and recommendations}

The world is changing rapidly and the future is largely vague and unknown. This awareness creates anxiety, frustration and confusion for individuals, affecting our well-being. We, as human beings, need to understand how our beliefs and emotions affect the way we perceive the world and influence our health and well-being. There appears to be a need for a practice such as mindfulness to counteract the high levels of stress and anxiety amongst learners within the current education system, especially those who grow up in challenging socio-economic contexts. In this context, it is important to educate a child in such a way that attention, awareness and listening skills are developed to allow for creative flexibility and application. A state of mindfulness would assist in optimising this process for the future generation (Lipton 2005; Pert 1997).

We believe that our study has shown, albeit in a small way, how the implementation of simple exercises in sound and listening can promote mindfulness in children. We assert that the knowledge and insights gained through this study demonstrate that deliberate and focused exposure to and active participation in music and sound can develop certain aspects of mindfulness in young children, subsequently optimising the education process. It is hoped that the research insights and findings emanating from the study will help to advocate for the core positioning of music and the arts, not only in the primary school curriculum but also in teacher education programmes. We furthermore believe that the research study also indicates that further implementation would prove useful in developing an education curriculum that has mindfulness at its core. We thus argue that mindfulness should form the basis of a more conscious education where the needs of the whole human being are integrated into the curriculum. Mindfulness, according to Burke and Hawkins (2012:39) endorses the primary goal of education, namely, to develop '.... an integrated individual who is capable of dealing with life as a whole'. It is indeed 'an idea whose time has come' (Burke \& Hawkins 2012:39).

We do acknowledge current lack of agreement with respect to the active ingredients of mindfulness training and ways to measure their effectiveness through rigorous scientific research (Meiklejohn et al. 2012). Well-established adult mindfulness training techniques still need to be further developed and refined for younger populations. Practical challenges with the implementation of mindfulness-based criteria within school settings constitute another reality. These would involve, for example, motivating educators to adopt mindfulness practices in schools, training teachers who are already practising some form of mindfulness, availability of time and physical space, supporting education policies and budgeting constraints.

As a start, we thus recommend that initial and continuing professional development teacher education programmes include mindfulness training as part of their teacher education syllabi. We also believe musical practice to develop aspects of mind fulness, especially at the primary school level can be used to incorporate related practices throughout the curriculum. In traditional societies, especially evident in Africa, music is seen as integral to all life (Deason-Barrow 2013). In modern education, it has unfortunately become marginalised and at best made into a 'subject' to be studied during a 'lesson'. Because of its real nature as an inherent ingredient of life, music should rather be viewed as the 'great holistic integrator at the core of the school's curriculum' (Deason-Barrow 2013:6). It is thus hoped that the research findings will also help to advocate the core positioning of music and the arts in the primary school curriculum.

\section{Acknowledgements Competing interests}

The authors declare that they have no financial or personal relationships which may have inappropriately influenced them in writing this article.

\section{Authors' contributions}

C.A. conducted the empirical study with guidance of A.C.D., who also co-authored the article.

\section{References}

Baer, R.A., Walsh, E. \& Lykins, E.L.B., 2009, 'Assessment of mindfulness', in F. Didona (ed.), Clinical Handbook of Mindfulness, pp. 153-168, Springer, New York.

Beach, M.C., Roter, D., Korthuis, P.T., Epstein, R.M., Sharp, V., Ratanawongsa, N. et al., 2013, 'A multi-centre study of physician mindfulness and health care quality', Annals of Family Medicine 11(5), 421-428. https://doi.org/10.1370/afm.1507

Beaulieu, J., 1987, Music and sound in the healing arts, Station Hill, New York, NY.

Berendt, J.E., 1983, The world is sound, Destiny Books, Rochester, NY.

Bicknell, J., 2009, Why music moves us, Palgrave Macmillan, New York, NY.

Bishop, S.R., Lau, M., Shapiro, S., Carlson, L., Anderson, N.C. \& Carmody, J., 2004, 'Mindfulness: A proposed operational definition', Clinical Psychology: Science and Practice 11, 230-241. https://doi.org/10.1093/clipsy.bph077 
Braun, V. \& Clarke, V., 2006, 'Using thematic analysis in psychology', Qualitative Research in Psychology 3(2), 77-101. https://doi.org/10.1191/1478088706qp063oa

Brown, K.W., Ryan, R.M. \& Creswell, J.D., 2007, 'Mindfulness: Theoretical foundations and evidence for its salutary effects', Psychological Inquiry 18, 211-237. https:// doi.org/10.1080/10478400701598298

Bunting, M., 2015, The mindful leader, Wiley, Milton, Queensland.

Burke, A. \& Hawkins, K., 2012, 'Mindfulness in education. Wellness from the inside out', Encounter: Education for Meaning and Social Justice 25(4), 30-41.

Campbell, D., 1997, The Mozart effect, Hodder \& Stoughton, London.

Cloete, E. \& Delport, A., 2015, 'Music education in the Grade R classroom: How three teachers learned in a participatory action inquiry', South African Journal of Childhood Education 5(1), 85-105.

Cohen, L., Manion, L. \& Morrison, L., 2007, Research methods in education, 6th edn., Routledge, London.

Creswell, J.W., 2013, Research design: Qualitative, quantitative and mixed method approaches, Sage, London.

Deason-Barrow, M., 2013, New impulses in music education inspired by anthroposophy An overview, Tonalis Music Centre, Leighterton.

Delport, A. \& Browne, E., 2015, 'Arts education in South African township schools: Teacher realities', in S. Schonmann (ed.), The wisdom of the many - Key issues in arts education. International yearbook for research in arts education, pp. 363-367, Waxmann, New York

Evans, G. \& Schamberg, M., 2009, 'Childhood poverty, chronic stress and adult working memory', Proceedings of the National Academy of Science 106, 6545-6549. https://doi.org/10.1073/pnas.0811910106

Feldman, G., Hayes, A., Kumar, S., Greeson, J. \& Laurenceau, J.P., 2007, 'Mindfulness and emotion regulation: The development and initial validation of the cognitive and affective mindfulness scale', Journal of Psychopathological Behavioural Assessment 29(3), 177-190. https://doi.org/10.1007/s10862-006-9035-8

Fellowship of the School of Economic Science, 2003, The letters of Marsilio Ficino, vol. 7, Shepheard-Walwyn, London.

Fresco, D.M., Moore, M.T., Van Dulmen, M., Segal, Z.V., Teasdale, J.D., Ma, H. et al., 2007a, 'Initial psychometric properties of the experiences questionnaire: A selfreport survey of decentering', Behavior Therapy 38(3), 234-246. https://doi.org/ 10.1016/j.beth.2006.08.003

Fresco, D.M., Segal, Z.V, Buis, T. \& Kennedy, S., 2007b, 'Relationship of post-treatment decentering and cognitive reactivity to relapse in major depression', Journal of Consulting and Clinical Psychology 75(3), 447-455. https://doi.org/10.1037/0022006X.75.3.447

Gardner, H., 2011, Frames of mind. The theory of multiple intelligences, Fontana, London.

Glennie, E., 2003, How to truly listen, viewed 09 March 2016, from https://www.ted com/talks/evelyn glennie shows how to listen?language=en\#t-1110719

Goldman, J., 2002, Healing sounds, Healing Arts Press, Rochester, NY.

Greene, M., 1995, Releasing the imagination. Essays on education, the arts and social change, Jossey-Bass, San Francisco, CA.

Greeson, J.M., 2009, 'Mindfulness research update, 2008', Complementary Health Practise Review 14(1), 10-18. https://doi.org/10.1177/1533210108329862

Grossman, P., Niemann, L., Schmidt, S. \& Walach, H., 2004, 'Mindfulness-based stress reduction and health benefits. A meta-analysis', Journal of Psychosomatic Research 57, 35-43. https://doi.org/10.1016/S0022-3999(03)00573-7

Hassed, C. \& Chambers, R., 2015, Mindfulness for well-being and peak performance Monash University, viewed 10 February 2016, from https://www/futurelearn/ com/courses/mindfulness-wellbeingperformance

Hedges, D.W. \& Woon, F.L., 2011, 'Early-life stress and cognitive outcome', Psychopharmacology 2014(1), 121-130. https://doi.org/10.1007/s00213-010 2090-6

Hornickel, J., Zecker, S., Bradlow, A. \& Kraus, N., 2012, 'Assistive listening devices drive neuroplasticity in children with dyslexia', Proceedings of the National Academic of Sciences of the United States of America 109(41), 16731-16736. https://doi. org/10.1073/pnas.1206628109
Huston, D., 2011, 'Mechanisms of mindfulness in communication training', Journal of Applied Communication Research 39(4), 406-421. https://doi.org/10.1080/00909 882.2011.608696

Ings, R., Jones, R. \& Randell, N., 2000, Mapping hidden talent, Youth Work Press, London. Jenny, H., 2001, Cymatics, Macromedia Publishing, Newmarket.

Kabat-Zinn, J., 2003, 'Mindfulness-based interventions in context: Past, present and future', Clinical Psychology: Science and Practice 10(2), 144-156. https://doi. org/10.1093/clipsy.bpg016

Kabat-Zinn, J., 2005, Coming to our senses, Hyperion, New York, NY.

Khan, H., 1996, The mysticism of sound and music, Shambala Press, Boston, MA.

Kokotsaki, D. \& Hallam, S., 2011, 'The perceived benefits of participative musicmaking for non-music university students: A comparison with music students' Music Education Research 13(2), 149-172. https://doi.org/10.1080/14613808.20 11.577768

Leeds, J., 2010, The power of sound, Healing Arts Press, Rochester, NY.

Le Mee, K., 1994, Chant: The origins, form, practise and power of Gregorian Chant, Bell Tower, New York, NY.

Lipton, B., 2005, The biology of belief, Hay House, New York, NY.

MacLaren, L., 2013, Music. The foundations of harmony, School of Economic Science, London.

Malinowski, P., 2013, 'Neural mechanisms of attentional control in mindfulness meditation', Frontiers in neuroscience $7(8), 1-11$. https://doi.org/10.3389/fnins. 2013.00008

Maxwell, J.A., 2012, Qualitative research design: An interactive approach, vol.41, Sage, London.

Menuhin, Y. \& Davis, C.W., 1979, The music of man, Methuen Publishing, London.

Meiklejohn, J., Phillips, C., Lee Freedman, M., Lee Griffin, M., Biegel, G., Roach, A. et al., 2012, 'Integrating mindfulness training into K-12 education: Fostering the resilience of teachers and students', Journal of Mindfulness, viewed 31 January 2016, from http://www.mindfulnesseverydat.info/pdf/WhitePaperMindfulnessInEducation.

Napoli, M., Krech, P.R. \& Holley, L.C., 2005, 'Mindfulness training for elementary school students: The attention academy', Journal of Applied Social Psychology 21(1), 99-125. https://doi.org/10.1300/J370v21n01_05

Newham, P., 1999, The healing voice, Element, Boston, MA.

Nugent, P., Moss, D., Barnes, R. \& Wilks, J., 2011, 'Clear(ing) space: Mindfulness-based reflective practice', Reflective Practice: International and Multidisciplinary Perspectives 12(1), 1-13. https://doi.org/10.1080/14623943.2011.541088

Pert, C., 1997, Molecules of emotion, Scribner, New York, NY.

Ramirez, J.P., Olvera, L.A., Nijmeijer, H. \& Alvarez, J., 2016, 'The sympathy of two pendulum clocks: Beyond Huygens' observations', Scientific Report, viewed 05 April 2016, from http://www.nature.com

Sahdra, B.K., Shaver, P.R. \& Brown., K.W., 2010, 'A scale to measure non-attachment: A Buddhist complement to Western research on attachment and adaptive functioning', Journal of Personality Assessment 92(2), 116-127. https://doi.org/ 10.1080/00223890903425960

Tallal, P., 2012, 'Improving neural response to sound improves reading', Proceedings of the National Academy of Science 109(41), 16406-16407. https://doi.org/10.1073/ pnas.1214122109

Thram, D., 2013, 'Understanding music's therapeutic efficacy: Implications for music education', in W.D. Bowman \& A.L. Frega (eds.), The Oxford handbook of philosophy in music education, pp. 129-138, Oxford University Press, Oxford.

Tunstall, T., 2012, Changing lives, Norton, New York, NY.

Vago, D.R. \& Silbersweig, D.A., 2012, 'Self-awareness, self-regulation, and selftranscendence: A framework for understanding the neurobiological mechanisms of mindfulness', Frontiers in Human Neuroscience 6, 296. https://doi.org/10.3389/ fnhum.2012.00296

Vermeulen, D., 2009, 'Implementing music in an integrated arts curriculum for South African primary schools', Unpublished PhD thesis, University of Pretoria, Pretoria.

Voss, A., 2001, 'Marsilio Ficino, the Second Orpheus', in P. Horden (ed.), Music as medicine, pp. 154-172, Ashgate, Burlington, VA. 